IZA DP No. 6371

Spillovers from Conditional Cash Transfer Programs:

Bolsa Família and Crime in Urban Brazil

Laura Chioda

João M. P. De Mello

Rodrigo R. Soares

February 2012 


\title{
Spillovers from Conditional Cash Transfer Programs: Bolsa Família and Crime in Urban Brazil
}

\author{
Laura Chioda \\ World Bank \\ João M. P. De Mello \\ Pontifical Catholic University of Rio de Janeiro \\ Rodrigo R. Soares \\ Pontifical Catholic University of Rio de Janeiro \\ and IZA
}

Discussion Paper No. 6371

February 2012

\author{
IZA \\ P.O. Box 7240 \\ 53072 Bonn \\ Germany \\ Phone: +49-228-3894-0 \\ Fax: +49-228-3894-180 \\ E-mail: iza@iza.org
}

\begin{abstract}
Any opinions expressed here are those of the author(s) and not those of IZA. Research published in this series may include views on policy, but the institute itself takes no institutional policy positions.

The Institute for the Study of Labor (IZA) in Bonn is a local and virtual international research center and a place of communication between science, politics and business. IZA is an independent nonprofit organization supported by Deutsche Post Foundation. The center is associated with the University of Bonn and offers a stimulating research environment through its international network, workshops and conferences, data service, project support, research visits and doctoral program. IZA engages in (i) original and internationally competitive research in all fields of labor economics, (ii) development of policy concepts, and (iii) dissemination of research results and concepts to the interested public.
\end{abstract}

IZA Discussion Papers often represent preliminary work and are circulated to encourage discussion. Citation of such a paper should account for its provisional character. A revised version may be available directly from the author. 


\section{ABSTRACT}

\section{Spillovers from Conditional Cash Transfer Programs: Bolsa Família and Crime in Urban Brazil}

This paper investigates the impact of Conditional Cash Transfer (CCT) programs on crime. Making use of a unique dataset combining detailed school characteristics with time and georeferenced crime information from the city of São Paulo, Brazil, we estimate the contemporaneous effect of the Bolsa Família program on crime. We address the endogeneity of CCT coverage by exploiting the 2008 expansion of the program to adolescents aged 16 and 17. We construct an instrument that combines the timing of expansion and the initial demographic composition of schools to identify plausibly exogenous variations in the number of children covered by Bolsa Família. We find a robust and significant negative impact of Bolsa Familia coverage on crime. The evidence suggests that the main effect works through increased household income or changed peer group, rather than from incapacitation from time spent in school.

JEL Classification: $\quad$ I28, I38, K42

Keywords: conditional cash transfer, Bolsa Família, crime, education, schooling, Brazil

Corresponding author:

Rodrigo R. Soares

Departamento de Economia

Pontifícia Universidade Católica do Rio de Janeiro

Rua Marquês de São Vicente, 225 - Gávea

22451-900 Rio de Janeiro, RJ

Brazil

E-mail: soares@econ.puc-rio.br

\footnotetext{
* The authors wish to thank Tulio Kahn and Alexandre Schneider for help with the data, and Joana Simões de Melo Costa and Priscilla Burity for outstanding research assistance. This paper benefited from comments from Tito Cordella, Anna Fruttero, and seminar participants at the World Bank's Workshop "Building the Evidence Base for Crime and Violence Prevention in Brazil" (Brasília, 2010), the $32^{\text {nd }}$ Meeting of the Brazilian Econometrics Society, and the $16^{\text {th }}$ LACEA Annual Meeting (Santiago, 2011).
} 


\section{Introduction}

Conditional Cash Transfer (CCT) programs, in which families receive government payments upon fulfillment of schooling and other requirements, are today among the most popular and celebrated social support programs in the world. Various versions of CCTs have been adopted in countries as diverse as Argentina, Bangladesh, Colombia, Indonesia, Jamaica, Kenya, Mexico, Turkey, and the US, among innumerous others. There is substantial evidence from some of these settings on the positive effects of CCTs on enrollment rates, preventive health care, and nutrition (for reviews of the literature, see Rawlings and Rubio, 2005, and Fizbein and Schady, 2009). Brazil, in particular, has one of the first and the largest CCT program in the world, currently named Bolsa Família. It covers over 11 million families and costs close to $0.4 \%$ of the country's GDP. Evidence suggests that Bolsa Familia has had substantial impact on enrollment rates, school progression, extreme poverty, and inequality, though there are questions related to its social rate of return and effectiveness in urban settings (Soares and Sátyro, 2009, and Glewwe and Kassouf, 2012).

This paper uses school and crime data from the city of São Paulo, Brazil, to present one of the first pieces of evidence on the effect of Bolsa Familia - or, for that matter, of any CCT program - on crime. ${ }^{1}$ Making use of a unique dataset combining detailed school characteristics with time and geo-referenced crime information, we estimate the contemporaneous impact of the number of children covered by Bolsa Familia within a school on crime in the school neighborhood. The number of children covered by CCT in an area at a moment in time is determined by the incidence of poverty and unemployment and by other socioeconomic characteristics, all likely to be correlated with crime. This precludes the interpretation of the correlation between Bolsa Familia coverage and crime as causal. We overcome this problem by exploiting the 2008 expansion of the program to adolescents aged 16 and 17, from an initial setting where maximum age of coverage was 15 . We construct an instrument that combines the timing of expansion and the initial demographic composition of schools to identify plausibly exogenous variations in the number of children covered by the CCT. This instrument allows us to estimate the causal impact of Bolsa Familia on crime. We find a robust and significant negative impact of Bolsa Familia transfers on crime. Our estimate suggests that the expansion of Bolsa Familia between 2006 and 2009, corresponding to roughly 59 more students covered per school, caused a $21 \%$ reduction in crime in school neighborhoods ( 94 fewer crimes per school per year).

\footnotetext{
${ }^{1}$ While writing the final version of this paper, we became aware of the work of Loureiro (2012). The author analyzes the effect of Bolsa Familia on poverty and crime rates in Brazil. But he uses a panel with state level data, where unobservables are likely to be an even more serious issue (Brazil has only 27 states, including the Federal District). Also, he adopts a very different identification strategy: his identification comes from state level deviations between actual and planned expansions of the program. He finds a strong effect of Bolsa Família on poverty, but only mild and non-robust effects on crimes (robberies, thefts, and kidnappings). In specifications including socioeconomic controls, his results suggest the absence of any significant impact of Bolsa Familia on crime.
} 
The potential relevance of CCTs as crime reducing instruments should indeed be expected, given that youth account for a disproportionately high fraction of crimes, and that there is an intimate relationship between education, socioeconomic conditions, and crime. In the US, for example, Levitt and Lochner (2001) document that $20 \%$ of the arrests for violent crimes involve individuals between ages 15 and 19 . In our data for São Paulo, among crimes for which the age of the suspected offender is known, between $20 \%$ and $25 \%$ of robberies, thefts, and motor vehicle crimes are supposedly committed by individuals below age 18 .

On education and crime, there are various potential channels in a two-way relationship. There is evidence on the effect of violence and crime on schooling and learning (see, for example, Grogger, 1997, Aizer, 2009, Rodríguez and Sanchez, 2009, Chambargwala and Morán, 2010, and Monteiro and Rocha, 2011) and also on the effect of schooling on involvement with crime and violence (see review by Lochner, 2010). Schooling may have long-term effects on criminal behavior through wages and preferences (discount rates and risk aversion), and, therefore, through the relative attractiveness of criminal activities and the cost of expected punishment (Becker and Mulligan, 1997, Lochner and Moretti, 2004, Lochner, 2010, Machin et al, 2010, and Deming, 2011). More importantly for this paper, schooling also has short-term impacts through an incapacitation effect, since time spent in school reduces the opportunity for certain types of crimes and risky behavior, though possibly also increasing the interaction among youth and the likelihood of violence. Anderson (2011), for example, documents declines in juvenile crime rates at the time of increase in minimum dropout ages across US states, while Berthelon and Kruger (2011) report reductions in crime and teenage pregnancy following a school reform in Chile that increased weekly school hours from 32 to 39 . Jacob and Lefgren (2003) and Luallen (2006), the former exploiting variations in teacher in-service days and the latter teacher strikes, document that property crimes decline but violent crimes rise when youth are in school (see also Snyder and Sickmund, 1999, and Gottfredson and Soulé, 2005).

But one of CCTs' main features is that it also implies monthly money transfers to families, and these may have direct impacts on criminal behavior. The ability to buy certain goods with transfers from the government may reduce the incentive or "need" to engage in economically motivated crimes. Additional income from welfare transfers may also alter households' routines in a manner that exposes them to less risk of victimization and/or opportunities for delinquency, such as by affording parents more time for supervision (Heller et al, 2010). Indeed, there is evidence that welfare transfers affect crime rates. De Franzo $(1996,1997)$, Zhang (1997), Hannon and De Franzo (1998), and Foley (2008) study the effect of the amount and timing of welfare payments, finding impacts on total number of crimes (negative) and also on the distribution of crimes through the month. Jacob and Ludwig (2010) analyze a housing voucher program in Chicago that transferred 
the equivalent of $50 \%$ of household income to beneficiaries, reporting a decline of roughly $20 \%$ in both violent and overall arrests, which implies an income elasticity of -0.4 .

A final channel through which CCTs may affect crime is social interaction. If the network or reference group of youth is affected by school enrollment and attendance, then staying in school may have positive peer effects (Glaeser et al, 1996, and Lochner, 2010), despite the higher probability of attrition between youths. This would be true as long as the school network were on average better than the peer group that youth would have in case they dropped out (or did not attend school).

The main challenge faced by this paper is to isolate the channel through which Bolsa Familia affects crime. Though we present robust evidence on the effect of Bolsa Familia transfers on crime, we are not able to directly address the issue of channel. Nevertheless, by looking at the heterogeneity of effects across days and types of crimes, we do provide some suggestive evidence on the channels that are likely to be at work in our setting. We find that the estimated effects of CCT on crime are virtually identical across school and nonschool days, suggesting that the incapacitation mechanism extensively discussed in the US literature is not the driving force behind our results. We also find the effects to be quantitatively more important for robberies, though there is also some evidence of reductions in drug-related crimes and crimes against minors. So the results indicate that the income component of Bolsa Familia is likely to be an important determinant of the reductions in crime, though social interactions through changed peer groups cannot be ruled out.

Our paper relates to three strands of literature. First, the paper adds to the numerous studies analyzing the impact of CCT programs by showing that spillovers onto other social phenomena, not directly targeted in the initial design of this type of program, may be significant and relevant from a policy perspective (see review in Fizbein and Schady, 2009). Second, it relates to the literature on educational policies and crime, and presents a context in which there is a reduction crime, but where incapacitation and future returns to schooling do not seem to be the main thrust. And third, the paper also speaks to the discussion on the socioeconomic determinants of crime. Various authors have documented a robust correlation between inequality and crime (see, for example, Fajnzylber et al, 2002, Bourguignon et al, 2003, Soares, 2004, or the discussion in Soares and Naritomi, 2010). To the extent that Bolsa Familia has had a substantial impact on inequality in Brazil (Soares and Sátyro, 2009), and that the income effect is likely to be an important force behind our results, the evidence presented here may be seen as an additional piece of information on the relationship between socioeconomic conditions and crime (in line with the evidence from welfare payments discussed before). 
The remainder of the paper is organized as follows. Section 2 provides an institutional background, by briefly describing the Bolsa Familia CCT program and Brazilian educational and law enforcement systems. Section 3 presents and discusses the data, while section 4 describes our methodology and identification strategy. Finally, section 5 presents the results and is followed by concluding remarks in section 6 .

\section{Institutional Background}

\subsection{The Bolsa Familia Conditional Cash Transfer Program}

Bolsa Família (or "Family Allowance") is Brazil's federal CCT program, created in 2003. Its creation was, in fact, the consolidation of various social support programs coupled with a redesign of Brazil's first federal CCT program, Bolsa Escola, which had been in operation since 2001. Bolsa Escola, in turn, was inspired by a series of pilot projects in various Brazilian cities, dating back to 1995 in the capital Brasília, and in Campinas and Ribeirão Preto, both in the state of São Paulo. Soares and Sátyro (2009) provide a history of Bolsa Família and a detailed discussion of its institutional design, as well as references to various impact evaluation studies.

Bolsa Família currently provides different benefits for families at different income levels and has various conditionalities. The Basic Benefit is a payment of $\mathrm{R} \$ 60.00$ for families with monthly per capita (p.c.) income below $\mathrm{R} \$ \mathbf{7 0 . 0 0}$. In addition, there is the Variable Benefit, according to which families with monthly p.c. income below $\mathrm{R} \$ 140.00$ receive $\mathrm{R} \$ 22.00$ per child under age 15 (up to the maximum of 3 payments). Finally, starting in 2008, benefits were extended to adolescents, through the creation of the Variable Youth Benefit. The Variable Youth Benefit paid R\$33.00 per family member aged between 16 and 17 (up to a maximum of 2 payments), for families with monthly p.c. income below $\mathrm{R} \$ 140.00 .^{2}$

The maximum benefit value in Bolsa Familia is $\mathrm{R} \$ 200.00$ per family, which applies to families with monthly p.c. income below R\$70.00, 3 children under age 15, and 2 adolescents aged between 16 and 17 . There are also schooling and health conditionalities attached to the payments, though recently it has been claimed that they are not seriously enforced. In terms of schooling, program participation requires school enrollment and 85\% attendance for children between 6 and 15, and 75\% attendance for adolescents between 16 and 17. Regarding health, conditionalities include fulfillment of a vaccination and growth and development calendar for children under 7, prenatal care for pregnant women, and health monitoring for lactating women.

It is important to mention that, during the period of our analysis, there was a second CCT program in operation in the city of São Paulo: the municipal program Renda Mínima (or “Minimum Income”). São Paulo's Renda Mínima is a minimum family income program created in 2006. In order to be eligible for the program,

\footnotetext{
${ }^{2}$ On January 2012, the exchange rate between the Brazilian Real and the US Dollar was 1.76 R\$/US\$.
} 
families must have lived in the city of São Paulo for at least 2 years, have monthly p.c. income below $R \$ 175.00$, and have at least one child under age 16. The conditionalities are school enrollment and minimum attendance of $85 \%$ for children between ages 6 and 15, and fulfillment of a vaccination calendar for children under 7 . Renda Mínima's benefits can complement those of Bolsa Familia. The maximum benefits allowed by Renda Mínima are $($ total value $=$ Bolsa Família + Renda Mínima) $: \mathrm{R} \$ 140.00$ for families with 1 child, $\mathrm{R} \$ 170.00$ for families with 2 children, and $\mathrm{R} \$ 200.00$ for families with 3 or more children.

Renda Mínima is sometimes used as a complement to Bolsa Familia, while sometimes families receive only one of the two benefits. Our CCT data, to be discussed in further detail below, is on the number of students per school receiving Bolsa Familia and Renda Mínima (with no information on value). The correlation of the number of Bolsa Familia and Renda Mínima recipients across schools is above 0.75 , making it very difficult to separate the independent effect of each program. In addition, we have an institutional change in Bolsa Familia that allows us to identify its causal impact, so we concentrate our analysis on the impact of the federal CCT program (also, the number of students covered by Bolsa Familia is $18 \%$ higher than that of Renda Mínima). We do however check whether results change if we incorporate Renda Mínima in the analysis and, more importantly, we use Renda Mínima as a way to validate our instrument.

Regarding the operational aspects of the program, Bolsa Familia is federally funded and jointly managed by the federal and municipal governments. Budgets for the program for each municipality are determined by the federal government, based on estimates of the number of poor families. Applications of families, eligibility verification, and final decisions on enrollment are managed by the municipality, conditional on the budget determined by the federal government (Glewwe and Kassouf, 2012). Schools play no direct role in operating or funding the program, apart from recording children's attendance. Payments are done by the Ministry of Social Development directly to individual family accounts, which can be accessed using bank cards distributed to families.

Thus, in our particular context, it is very unlikely that CCT allocation takes into account differences in violence within the city of São Paulo. However, the program targets poor families, and areas with different concentration - or dynamics - of poverty are likely to have different levels - or dynamics - of crime, be it due to socioeconomic conditions, to other policies, or to different intensity and style of policing.

\subsection{Law Enforcement}

Law enforcement in Brazil is primarily the responsibility of state governments. Executive and administrative authority rests with the state secretariats of public security (Secretarias Estaduais de Segurança Pública), which are appointed and respond directly to the governor, who also allocates the budget to the 
secretariats. Some strategic decisions are determined by law. For example, by constitutional mandate, the number of policemen in the state of São Paulo has to be roughly constant in per capita terms across cities. The execution of enforcement is shared between two corporations that respond to the secretariats: the military police, responsible for ostensive patrolling and repression, and the civil police, which is judiciary and investigative. The commanders of the two police forces are appointed by the governor. There are also municipal police forces (Guardas Civis Municipais), which are not mandatory by federal law but a choice of the municipality. These can be used to reinforce ostensive patrolling, traffic and crowd control, but have less authority and a reduced scope in comparison to the state polices. The city of São Paulo has its municipal police force. Crime recording and monitoring of public security conditions are, nevertheless, responsibility of the state polices.

\subsection{Education}

Primary and secondary schooling in Brazil is mainly responsibility of cities and states. In general, cities focus on elementary and middle schools (pre-school to $8^{\text {th }}$ grade), and states focus on middle and high schools. In the city of São Paulo, 98\% of municipal schools offer middle school grades and none offers high school, while, among state schools, 93\% offer middle school grades and 99\% offer high school.

Pupil allocation to schools is based on residence location. There are no official school districts, but the city and state secretariats form a committee, which enroll the pupil at the closest available school. Once the child enters a school, she stays there unless the family moves from the original neighborhood. Parents cannot choose schools, except for a couple of high-performance flagship schools - which have enrollment rationed through entrance exams - and for decisions on neighborhood of residence. There is no evidence that public schooling is an important dimension in neighborhood choice in Brazil.

Given the system of assignment of pupils to schools, it is unlikely that students with particular characteristics (more or less violent, for example) are deliberately sent to schools with more Bolsa Familia coverage. However, again, students from poorer families will be clustered in schools in poorer neighborhoods, which are likely to have higher coverage of Bolsa Familia and higher crime rates. Similarly, changes in local economic conditions and other policies may simultaneously affect eligibility of families to the CCT program and the incidence of crime in a certain area. To give a concrete example, consider the minimum wage increase from $R \$ 300$ to $R \$ 465$ between 2006 and 2009, corresponding to a 55\% gain in nominal terms and a 30\% gain in real terms. To the extent that minimum wages impact mostly low-income families, this change should affect the correlation between CCT coverage and crime. This is the type of concern we have in mind when developing our empirical strategy in section 4. 


\section{Data}

\subsection{Crime Data}

Our crime data are from the INFOCRIM database, a COMPSTAT-like crime tracking system from the Secretaria de Segurança Pública do Estado de São Paulo, the state law enforcement agency. We have time and geo-referenced data for all reported crimes in the city of São Paulo, from 2006 through 2009. INFOCRIM includes all information available from the police reports. It includes location of occurrence (translated into latitude and longitude), type of crime, estimated time of occurrence, and, sometimes, characteristics of the suspected offender, such as age and gender. Unfortunately, age of the suspected offender is available only for a very small fraction of the sample. Therefore, due to concerns about sample selection, we do not use this specific information. We concentrate our analysis on thefts, robberies, acts of vandalism, violent crimes, drugrelated offenses, and crimes against minors. ${ }^{3}$ Records related to these offenses encompass a total of $1,473,939$ crimes over the 4 years in our sample.

\subsection{School Data}

Our school and student data cover the period between 2006 and 2009 and come from two sources. From the Secretaria de Educação da Cidade de São Paulo, we have data on state and municipal schools identifying the type of school, school location (translated into longitude and latitude), and number of students covered by conditional cash transfer programs (separate information on number of students receiving Bolsa Familia and Renda Mínima). From the Brazilian School Census, we gather additional information on number and demographic characteristics of teachers and students, and school infrastructure. The characteristics are: education of teachers; gender, race, and current grade of students; and number of classrooms, availability of treated water, sanitation, and TV, and number of computers.

\subsection{Unit of Analysis}

Given the data, nature of the phenomenon, and policy we are studying, geographic areas associated with particular schools should be the natural unit of analysis. Unfortunately, as mentioned before, São Paulo does not have a strict geographic definition of school districts. Still, students in the city are allocated to slots available in the closest school, so there is a high correlation between school location and neighborhood of

\footnotetext{
${ }^{3}$ Thefts and robberies are defined in the usual way (burglaries are subsumed within both categories, according to the existence or not of physical interaction). The other categories include the following definitions of crimes from the police records (our translation): (i) violent crimes include assaults, attempted homicides, attempted rapes, homicides, rapes, random acts of violence, and threats; (ii) drug-related crimes include association with/for drug-trafficking, drug-trafficking (sale), manufacturing of drugs, possession of drugs, and use of drugs; (iii) vandalism includes cruelty to animals, damage to property, obscene writing, disturbance of the public order, causing turmoil, and vagrancy; and (iv) crimes against minors include abandonment, abuse, corruption, enticement, and facilitating the prostitution of minors, mistreatment, and surrendering of minors to persons of ill repute.
} 
residence. Therefore, we create artificial school districts by assigning to a given school the area that is closer to it than to any other school.

This is a key step that allows us to link crimes happening in a given location to a particular school. Obviously, children do not circulate only in these areas and do not necessarily live there, but they are likely to live close to the school and spend part of their day there. If there is a high probability that children are around the school area for a significant amount of time, this approach should be adequate. US evidence supports this strategy, since it reveals a concentration of crimes committed by youth in periods immediately after school hours, when children/adolescents are still likely to be near the school (Snyder and Sickmund, 1999, Jacob and Lefgren, 2003, and Gottfredson and Soulé, 2005). The system of allocation of students to schools in São Paulo also supports our approach, as children are expected to study in the closest school available. Hence, our measure of crime per school is the number of crimes that were committed closer to a given school than to any other school (these crimes are "assigned" to that particular school). ${ }^{4}$

The construction of our dependent variable depends, therefore, on the schools included in the sample. Generally, the number of crimes assigned to a given school can vary with the full set of schools considered. Given the typical age of students, we focus on middle and high schools (from $5^{\text {th }}$ to $11^{\text {th }}$ grade) and start by generating the number of crimes per school considering three different samples: only high schools, only middle schools, and middle schools and high schools together. ${ }^{5}$ This allows us to check the robustness of the results to different formulations and also to assess how the response of crime varies with the age of children. Based on the age composition of students, it is likely that high schools - with older adolescents - would be the more adequate unit for our analysis.

\subsection{Descriptive Statistics}

Table 1 provides descriptive statistics for the three samples we generate: one composed only of middle schools, another composed only of high schools, and a third one composed of middle schools and high schools together. The unit of observation is the school, and all crime statistics refer to the definition of school districts discussed in the previous section.

High schools are less numerous than middle schools. Thus, by construction of our metric of crime around schools, there is more crime around high schools than middle schools, since the former covers a larger area than the latter. Otherwise, crime follows similar patterns around high and middle schools. Regarding

\footnotetext{
${ }^{4}$ For each crime, we calculate the distance from the location of occurrence to every school in the sample. We subsequently assign that crime to the closest school.

${ }^{5}$ Though we refer to middle schools and high schools as if they were separate institutions, strictly we should be writing "schools offering middle school grades" and "schools offering high school grades," since the same school can offer middle and high school simultaneously. We keep the terms used in the text as shorthands for these.
} 
specific types of crimes (not shown in the table), robbery is the most common, followed by violent crimes. The incidence of theft is lower than that of violent crimes, suggesting a considerable degree of underreporting for lesser crimes. Categories such as vandalism, drug-related and crimes against minors have substantially fewer occurrences, indicating that it may be difficult to estimate the impact of Bolsa Familia for these categories.

Table 1 also presents descriptive statistics for the fraction of students aged between 16 and 17 in 2006, which plays an important role in the construction of our instrument and the identification of the causal effect of Bolsa Familia (see next section). In high schools, 28\% of pupils were 16 and 17 years old in 2007, with a standard deviation of $11 \%$. This is important for our purposes because our main strategy relies on the presence and variation of 16 and 17 year-olds across schools. In middle schools, the fraction of 16 and 17 yearolds is smaller, as expected.

High schools have on average 1,360 students, whereas middle schools have 1,248 students. Finally, Bolsa Família covers $9 \%$ of high school students and $13 \%$ of middle school students. The higher coverage in middle schools is expected because, until 2008, eligibility to Bolsa Família was restricted to children below age 15. Also notice that there is substantial variation in the number of children covered by the CCT across schools, reflecting both different number of students and different socioeconomic conditions across areas.

\section{Empirical Strategy}

The main challenge in the identification of the causal effect of CCTs on crime comes from the fact that targeting implies that CCT coverage is correlated with socioeconomic conditions, which, in turn, can be correlated with crime. This potential problem is present in both the cross section - as when poorer areas have higher CCT coverage and higher crime - and the time series - as when areas experiencing economic improvements see reductions in CCT coverage and reductions in crime rates. So, for example, fixed-effects, despite being important for controlling for unobserved characteristics, would not be enough to overcome the endogeneity problem. In short, the fraction of children covered by the program each year is likely to be a direct function of socioeconomic conditions in the area at that point in time, which may in turn have an independent impact on crime rates. From this perspective, we could find a positive correlation between CCTs and crime simply because increased coverage is associated with deteriorating socioeconomic conditions.

In addition to controlling for school fixed-effects and several variables related to infrastructure and teachers and students characteristics, we adopt an instrumental variables approach to try to overcome this problem. As mentioned before, in 2008 Bolsa Familia extended its benefits to adolescents between ages 16 and 17, through the Variable Youth Benefit. From then on, families with monthly p.c. income below $\mathrm{R} \$ 140.00$ 
would receive $\mathrm{R} \$ 33.00$ per family member between ages 16 and 17 , up to a maximum of 2 . Relying on the different demographic composition of schools, we can construct an instrument for CCT coverage that exploits the interaction of number of students between 16 and 17 in the first year in the sample (2006) with the timing of program expansion. If there is an impact of conditional cash transfers on crime, then when Bolsa Familia is expanded one should expect a larger reduction in crime around schools that had a higher fraction of students between 16 and 17 before program expansion.

Our benchmark specification is the following:

$$
\ln \left(\text { crime }_{i t}\right)=\alpha+\beta\left(C C T_{i t}\right)+\gamma^{\prime} X_{i t}+\theta_{i}+\delta_{t}+\varepsilon_{i t},
$$

where crime $_{i t}$ denotes the number of crimes in school $i$ and year $t ; C C T_{i t}$ is the number of students receiving CCT; $X_{i t}$ is a set of school variables related to infrastructure, and teachers and students characteristics; and $\vartheta_{i}$ and $\delta_{t}$ are, respectively, school and year fixed-effects. In all specifications, standard errors are clustered at the school level, so that the error term is allowed to have an arbitrary correlation within schools over time. Our instrument for $C C T_{i t}$ is the interaction of number of students between ages 16 and 17 in 2006 with a dummy variable equal to one in 2008 and 2009, years in which program coverage was expanded to those ages.

As we do not have a measure of local population, which would be the natural way to normalize the number of crimes in a given area, we use the natural logarithm of number of crimes as the dependent variable. We control for the number of children in the school in the right hand side, since they are potential offenders and victims. Furthermore, given that children from different schools interact and migrate across boundaries of our definition of school districts, in some specifications we also control for the number of children in neighboring schools. To construct this variable, we count the number of students enrolled in schools within two kilometers of a given school.

Our full set of controls includes the following information from the Brazilian School Census: number of students enrolled, average years of schooling of teachers, student-teacher ratio, number of students per class, availability of sewage, availability of treated water, availability of TVs for students, availability of computers for students, fraction of non-white students, fraction of female students, fraction of delayed students, and, in some specifications, number of students enrolled in schools within 2 kilometers. These are intended to capture, above all, socioeconomic conditions of the area where the school is located (or, similarly, of the students' families) and impacts of other competing policies that may have similar effects to those expected from CCTs.

One last issue in our estimation is the fact that the dependent variable is the number of crimes in relatively small areas. In contexts of count data, such as this, there are concerns related to the functional form 
of the estimating equation, given the possibility of an excessive number of zeros and over-dispersion. In our setting, excessive zeros do not seem to be a serious issue, but over-dispersion may be a problem (see Figure A.1 in the Appendix). For this reason, in addition to linear regressions with the dependent variable in natural logarithms (substituting undefined values by zero), we also estimate Poisson and negative binomial models. In all three cases, coefficients can be interpreted as semi-elasticities.

Finally, in trying to understand the channels through which Bolsa Familia affects crime, we also estimate our benchmark specification for different types of crimes and for crimes committed in different days of the week and at different hours.

\section{Results}

\subsection{Benchmark Specification}

Panels $A, B$, and $C$ in Table 2 present the results of our benchmark specification for the three alternative samples: only middle schools, only high schools, and middle and high schools together. In order to clarify the type of variation contained in the data and the role played by our instrument, each panel consists of five columns: the first one displays the result of a simple regression of log of crimes on number of students receiving Bolsa Famila and time dummies, with no additional controls; the second column adds our set of controls to this specification (students, teachers, and school characteristics); the third column adds school fixed effects; the fourth columns presents a reduced form regression of log of crimes on our instrument and the full set of controls (the instrument is the interaction of number of students between ages 16 and 17 in 2006 with a dummy equal to 1 in 2008 and 2009); and the last column presents our IV estimates, where number of students receiving Bolsa Familia is treated as endogenous.

Qualitative results are identical across the three samples, so we concentrate the discussion on our preferred sample, high schools, and leave quantitative considerations for later. Looking at column 1 in Panel B, one can see a negative correlation between number of students receiving Bolsa Familia and crime in the school neighborhood. This correlation is not associated with observable characteristics of schools, teachers, and students, since the coefficient remains virtually unchanged when we add the controls in column 2 . But in column 3, when we add school fixed effects, the negative correlation between CCT coverage and crime disappears and the estimated coefficient becomes very small in magnitude and non-significant. These first three columns suggests that there is some cross-sectional variation in Bolsa Familia coverage that seems to be negatively associated with crime, but that the within school variation in coverage bears no noticeable relationship with crime rates. This could be the case if, for example, there was a more or less random variation 
in coverage across school, but coverage within a school over time responded to neighborhood conditions. The latter would be expected if, for example, any improvement in local economic conditions were associated with reduced Bolsa Familia eligibility and reduced crime. The real gain in minimum wages mentioned before could be one force generating this type of correlation, but any other factor determining local development would also work in this direction.

The within school variation in CCT coverage seems to isolate the most endogenous dimension of variation in our independent variable. Therefore, if we want to use school fixed effects to control for unobserved neighborhood characteristics, we need to use our instrument for Bolsa Familia coverage. Column 4 presents a reduced form regression of crime on our instrument, showing that the instrument is negatively correlated with crime rates. In short, schools with a higher number of students between ages 16 and 17 in 2006 experienced larger declines in crime in 2008 and 2009, when the CCT coverage was expanded to these age groups. In column 5 , we use the instrument to isolate the supposedly exogenous dimension of variation in Bolsa Familia coverage. The coefficient is negative and statistically significant and, surprisingly, almost identical to the coefficients presented in columns 1 and 2, where we did not use school fixed effects. So, for the case of high schools, the simple conditional correlation between CCT coverage and crime seems to give a very accurate estimate of the causal effect. The key identifying assumption here is that the age composition of schools in 2006 was indeed associated with changes in coverage after 2008 and that, additionally, there was no other connection between age composition and variations in crime apart from that working through CCT coverage. ${ }^{6}$ We present some evidence to support these two assumptions in the following tables.

The results across the three samples in Table 2 are qualitatively very similar, but have some noticeable quantitative differences. First and most importantly, the estimated effects of Bolsa Familia on crime are stronger for high schools than for the other two samples. Since high schools have the older children and adolescents, which indeed should be expected to be more actively involved in crime, this should be expected. Overall, the estimated coefficients for high schools are at least $100 \%$ larger than the analogous ones for the other two samples. Furthermore, the coefficient is much more stable across columns 1, 2 and 5 in the high school sample. This suggests that, looking at column 1, the endogenous dimension of variation in Bolsa Família is a more serious issue for middle schools than for high schools. For all these reasons, and also because high schools constituted our preferred sample since the beginning, we concentrate the results presented in the remainder of the paper on the high school sample and on the specification from column 5.

\footnotetext{
${ }^{6}$ Notice that a direct connection between initial age composition and level of crime does not threaten identification, since it is subsumed in the school fixed effects. The only threat to identification would be an independent connection between initial age composition and subsequent variations in crime.
} 
Table 3 presents the first stage of our instrumental variable strategy. In order to clarify the type of variation identified by the instrument, we present three specifications: the first one is a simple regression of Bolsa Familia coverage on the instrument and time dummies; the second one includes school fixed effects; and the last one, which is the actual first stage related to column 5 of Table 2, includes all controls. The most important point from Table 3 is that in column 1, before we include school fixed effects, there is no correlation between the instrument and CCT coverage. This comes from the negative cross-sectional correlation between number of students aged 16 and 17 and Bolsa Familia coverage, since the main focus of the program is children below age 15. But once school fixed effects are introduced in column 2, we see a positive and significant relationship between the instrument and CCT coverage. The coefficient rises in magnitude and becomes estimated more precisely when we introduce additional controls in column 3 . The point estimate implies that 100 more students between 16 and 17 in 2006 would be associated with 4 more students covered by Bolsa Familia after 2008, corresponding to a $4 \%$ coverage in this age group (which seems to be in line with the overall coverage of $9 \%$ in high schools from Table 1). This final specification is the one indeed used in our instrumental variable approach, and the F statistic displayed in the table suggests that the instrument plays an important role in explaining variations in CCT coverage, so that we do not have a weak instrument problem.

Going back to the results from Table 2, let us analyze the quantitative implications of the estimated coefficient. To get a feeling of its practical significance, consider the following counterfactual exercise. In 2006, a median high school had 70 students receiving Bolsa Familia, while in 2009 this number was 129. Using the estimate from column 5 in Panel B, the impact of this Bolsa Familia expansion on crime would be:

$$
\begin{aligned}
\ln (\text { Crime } \mid B F= & 129)-\ln (\text { Crime } \mid B F=70)=-0.00391 \times 59 \leftrightarrow \ln \left(\frac{\text { Crime } \mid B F=129}{\text { Crime } \mid B F=70}\right)=-0.23069 \\
& \leftrightarrow \frac{\text { Crime } \mid B F=129}{\text { Crime } \mid B F=70}=e^{-0.23069}=0.793986
\end{aligned}
$$

that is, 59 more students covered by Bolsa Familia - or 0.62 of a standard deviation - would have caused a $21 \%$ reduction in crime. Considering the median number of crimes in the sample, this would correspond to 94 fewer crimes per year in each school neighborhood (or 0.12 of a standard deviation).

The benchmark results from Table 2 demand several comments. There is a remarkable difference between the fixed effects and the IV-fixed effects estimates, as well as a remarkable similarity between the IVfixed effects and the between estimates from columns 1 and 2. As mentioned before, we interpret these differences and similarities as evidence that the within variation is particularly endogenous: after discarding all common time-series variation, within variation in crime is most likely driven by differences in socioeconomic 
dynamics across neighborhoods. Bolsa Família, in turn, probably penetrated more rapidly in deteriorating places. Our instrument corrects for that.

It is also useful to recall the margin along which this parameter is estimated. With heterogeneous treatment effects, the IV estimate represents the average reduction in crime among those areas most affected by the expansion in Bolsa Família, i.e. areas with lots of low income 16 and 17 year-olds. In all likelihood, these are precisely the youth who are at most risk of involvement in crime and violence and who would engage in illicit acts in the absence of the CCT. The magnitudes reported here are therefore not implausible: the Bolsa Familia expansion is recruiting into school and transferring money to precisely those individuals who are most at risk of involvement in crime, namely adolescents aged 16 and 17 from poor households.

\subsection{Robustness}

We now address some potential concerns related to our benchmark results. We first analyze whether incorporating the municipal CCT program (Renda Mínima) affects the results, then consider potential spillovers of crime across school neighborhoods, and finally address issues related to the functional form of the estimating equation. In addition, the municipal CCT program allows us to provide some evidence to validate the exclusion restriction of our Bolsa Familia instrument.

As mentioned in section 2, Renda Mínima is a municipal CCT program that sometimes complements and sometimes replaces Bolsa Família. We do not have an institutional change analogous to the expansion of Bolsa Familia coverage that would allow us to estimate an independent causal effect of Renda Mínima. Therefore, it is not obvious how the municipal CCT program should be incorporated in our analysis. One alternative would be to sum the total number of children in each school receiving either Bolsa Familia or Renda Mínima to create an aggregate variable for CCT recipients, and then instrument this variable with the same instrument that we constructed for Bolsa Familia. The problem with this procedure would be the possibility of double counting, since for some families the municipal program complements the federal one. Another alternative would be simply to include Renda Mínima coverage as an additional control in our estimation. The problem with this alternative would be that Renda Mínima suffers from the same endogeneity issue discussed before, so that its coefficient - and potentially also the other estimated coefficients - would be biased. Since there is no clearly dominant strategy between these two, we apply both.

In the first three columns from Table 4, we present the results from these exercises. In the first column, we present the result from the first stage regression when we consider the sum of recipients of Bolsa Família and Renda Mínima as the total CCT coverage per school, while in the second column we present the second stage of this same exercise. Results from both the first and second stages are very similar to those obtained 
before, though the coefficients are estimated slightly less precisely. In the third column, we present the results when we include Renda Mínima as an additional control. Though the coefficient on the municipal CCT appears as positive and statistically significant, the coefficient on the Bolsa Familia variable (instrumented) remains very similar to what was obtained before. Given our previous discussion on the endogeneity of CCT coverage, the positive coefficient on Renda Mínima should be no surprise. The important point from these first three columns is that, irrespective of how one wants to incorporate Renda Mínima in the estimation, there is no substantial change on the estimate of the causal impact of Bolsa Familia on crime.

But the municipal CCT program also offers an unusual opportunity for us to validate our instrument. One potential concern is that the initial demographic composition of schools might be correlated with specific neighborhood characteristics, which, in turn, might be associated with the evolution of socioeconomic conditions and crime rates over time. If that was the case, our second and first stage results from Tables 2 and 3 would be spurious, reflecting simply the differential dynamic behavior of neighborhoods with a large number of teenagers around ages 16 and 17. If that was the case, we should expect our strategy to also deliver similar results when, instead of considering the Bolsa Família program, we consider Renda Mínima. The latter was not expanded to encompass 16 and 17 year-olds, so our instrument should not work when we consider Renda Mínima alone and ignore Bolsa Família. If it did work in this setting, this should raise serious doubts regarding our identification strategy.

In columns 4 and 5 of Table 4 we conduct this exercise. We ignore Bolsa Familia coverage and concentrate solely on Renda Mínima. We then run our most complete specification, corresponding to column 5 in Table 2, and to column 3 in Table 3. Column 4 in Table 4 shows that there is no significant correlation between our instrument and Renda Mínima coverage. In reality, the point estimate is negative but far from statistically significant. In column 5, we show that the second stage of this exercise also delivers nonsignificant results, which do not carry much meaning anyway given the failure of the first stage. Using our instrument based on institutional changes to the Bolsa Familia CCT program, we are not able to generate exogenous variation nor to identify any causal effect of the Renda Mínima CCT program, which was not subject to the same institutional change. These results should be expected if the exclusion restriction implicit in our instrumental variable approach was met. This indeed seems to be the case.

Another potential concern is related to the geographic dimension of the problem and the possibility of migration of youth across school neighborhoods. Areas surrounded by a large number of schools with several students may be subject to more crime because a larger number of students circulate and interact with each other. We address this issue by calculating the total number of students in schools within a certain distance 
from a given school and including it as an additional control in our benchmark specification. Our variable is the total number of students in schools within two kilometers of a given school. Column 6 in Table 4 presents the result of a regression that controls for this additional variable. The point estimate on the Bolsa Familia variable (instrumented) remains again very similar to that obtained before. So accounting for the geographic distribution of schools and the possibility of migration of youths across school neighborhoods makes virtually no difference to our initial results. Interestingly, we find that the number of students within two kilometers of a given school has a positive and significant impact on the number of crimes in the school neighborhood. But the impact is quantitatively very small: a 1 standard deviation increase in the number of students within two kilometers $(5,963)$ would be associated with 0.5 more crime per year in the school neighborhood.

Finally, we address potential concerns related to the functional form of the estimating equation. Our dependent variable is a non-negative integer, and the number of crimes in some areas is small. Count data models are arguably more adequate for estimation in this context, where an excessive number of zeros or over-dispersion may raise specification concerns (Wooldridge, 2002). In our case, when all crimes are considered, over-dispersion seems to be potentially important, but an excessive number of zeros does not seem to be an issue (see Figure A.1 in the Appendix). ${ }^{7}$ Still, we re-estimate our benchmark specification using Poisson and Negative Binomial models. For the case of Poisson, we estimate all specifications corresponding to columns 1 to 5 in Table 2. For the Negative Binomial, we estimate only specifications corresponding to the instrumental variable regression from column 5 in Table 2. Given the non-linearity present in all these models, the instrumental variable strategy is implemented using control functions and standard errors are bootstrapped. ${ }^{8}$ The coefficients in these count models can be interpreted as semi-elasticities, so that they can be directly compared to the results obtained before.

The results are displayed in Table 5. The first five columns reproduce the columns from Table 2 using the Poisson instead of the log-linear model. Qualitative results are identical, though point estimates are a little different and vary more from specification to specification. Most notably, the results of the simple Poisson models tend to be larger than the corresponding log-linear specifications, while that of the instrumental variable strategy is somewhat lower. The last column presents the results when we use the instrumental variable strategy with the Negative Binomial. The Negative Binomial coefficient, which accounts for over-

\footnotetext{
${ }^{7}$ The average number of crimes around high schools and middle schools is, respectively, 634 and 377 . Zeros occur $0.17 \%$ and $0.26 \%$ of observations in each case.

${ }^{8}$ In both cases we use the fixed-effect transformation (subtracting the mean overtime for each cross section unit), and bootstrap standard errors re-drawing and re-estimating both the first-stage and the second stage including the estimated residual. Under certain assumptions, this procedure will eliminate the fixed-effect even in non-linear models such as the Negative Binomial and the Poisson. See Cameron and Triverdi (2005).
} 
dispersion, is much larger than the corresponding Poisson result, coming closer to the point estimate from column 5 in Table 2. Overall, issues related to functional forms and count data do not seem to influence the main results presented before.

\subsection{Channels}

The last challenge of this paper is to identify the channels through which Bolsa Familia affects crime. As mentioned, there are at least three potential channels in this relationship: incapacitation from time spent in school, income effects from government transfers, and social interactions from changed peer group.

One way to address whether incapacitation seems to be at work is by looking at the effect of Bolsa Familia on crime by day and time of occurrence. Finding larger effects on school days would in principle suggest an important role for the incapacitation effect, whereby time spent in school "crowds-out" opportunities for delinquency. We classify each crime in our sample as having occurred on a school or on a non-school day, corresponding to days with and without classes (non-school days are defined as weekends, holidays, vacations, etc). We also classify crimes as having occurred in the morning (6:00am-12:00pm), afternoon (12:00pm-6:00pm), evening (6:00pm-12:00am), and night (12:00am-6:00am). In this classification, high school classes are typically held in the morning or in the afternoon. Following, we run our benchmark instrumental variable specification for crimes that occurred in different days and at different times. Results are presented in Table 6.

The overall effect of Bolsa Familia on crime is very similar across school and non-school days, being even slightly larger for days without classes. This suggests that incapacitation effects are not a relevant channel behind the impact of CCT on crime. In terms of the hours of occurrence, on days with classes, the effects of Bolsa Familia are concentrated in the afternoon and at night, while there are significant effects in the morning, evening, and night in days without classes. But coefficients are estimated with less precision when we look at crimes by time of the day, so one should not attach too much weight to these results. In any case, no point estimate displays a positive sign, indicating that there is no evidence of a simple displacement of crime across hours within a day.

Having ruled out incapacitation as the main channel linking Bolsa Familia to crime, we move on to analyze the impact of the CCT program by type of crime. Types of crimes may reveal whether impacts are larger in economically motivated crimes, or in more "behavioral" crimes, shedding light on the potential role of the two remaining mechanisms. We therefore look at the effect of Bolsa Familia on robberies, thefts, violent crimes, vandalism, drug-related offenses, and crimes against minors. Results are presented in Table 7. 
The table shows significant negative impacts of Bolsa Familia on robberies, drug-related offenses, and crimes against minors. Thefts are seemingly unaffected, although this category is poorly measured, suffering from serious underreporting problems (as previously discussed). Point estimates are larger for drug-related offenses and crimes against minors, but the averages of these crimes are much lower than that of robbery (3 and 5, respectively, against 433). This implies that most of the quantitative impact of the CCT on crime comes from robberies. There also seems to be a negative correlation between Bolsa Familia and violent crimes, but the coefficient is much smaller in magnitude and only borderline statistically significant. Overall, the evidence from the heterogeneous impact of Bolsa Familia on different types of crimes suggests that economically motivated crimes (robberies) are the main driving force in the quantitative response of crime to CCT coverage. Still, given the evidence on the response of violent crime, drug-related offenses, and crimes against minors, one cannot entirely rule out some effect through peer groups and social interactions, and even indirect income impacts through changed household routines, as suggested by Heller et al (2010). Drug-related offenses are probably a combination of economically motivated and "behavioral" crimes, while violent crimes are likely to be mostly the latter. Crimes against minors, in turn, are likely to be very sensitive to household organization and family routines, which may change as a response to increased income.

\section{Concluding Remarks}

This paper combines detailed crime data from the city of São Paulo with information on Bolsa Familia coverage per school to provide one of the first pieces of evidence on the effect of CCTs on crime. We overcome the problem of endogeneity of CCT coverage by exploiting an institutional change to the Bolsa Familia program that expanded coverage to older age groups. Combining the initial demographic composition of schools with the timing of institutional change, we construct an instrument that identifies an exogenous dimension of variation in the number of children covered by the CCT. This instrument allows us to show that CCT coverage in a school has a negative impact on crime in the neighborhood. The evidence also indicates that the reduction in crime is not concentrated in school days and seems to be mostly driven by economically motivated crimes (robberies). So it is likely that the incapacitation effect from time spent in school is not a particularly relevant mechanism, while the income component of CCTs seems to play an important role.

Our paper speaks directly to the literature on impact evaluations of CCTs by showing that the reductions in poverty and inequality associated with these programs have broader social consequences, which should be taken into account in program design and evaluation. Narrow impact evaluations of these interventions, focused on very specific dimensions, should therefore be taken with a grain of salt. The results 
also contribute to the literature on determinants of crime, by presenting an additional piece of evidence on the relationship between socioeconomic conditions and crime: Bolsa Familia has been heralded as an effective and low cost instrument to fight inequality; our results suggest that the reduction in inequality determined by the program was accompanied by reduced crime rates, reinforcing the connection between inequality and crime stressed before in the literature.

\section{References}

Anderson, D. Mark (2011). "In School and Out of Trouble? The Minimum Dropout Age and Juvenile Crime." Unpublished manuscript.

Aizer, Anna (2009). Neighborhood Violence and Urban Youth. In: Jonathan Gruber (ed). The Problems of Disadvantaged Youth - An Economic Perspective. NBER and University of Chicago Press, 2009.

Becker, Gary and Casey B. Mulligan (1997). The Endogenous Determination of Time Preference. Quarterly Journal of Economics, 112(3), 729-58.

Berthelon, Matias E. and Diana I. Kruger (Forthcoming). Risky behavior among youth: Incapacitation effects of school on adolescent motherhood and crime in Chile. Journal of Public Economics, 95 (1-2), 41-53.

Bourguignon, François, Jairo Nuñez, and Fabio Sanchez (2003). A Structural Model of Crime and Inequality in Colombia. Journal of the European Economic Association, 1(2-3), April/May, 440-449.

Cameron, A. Colin and Pravin Triverdi Microeconometrics: Methods and Applications, Cambridge: Cambridge University Press, 2005.

Chamarbagwala, Rubiana and Hilcías E. Morán (2011). The human capital consequences of civil war: Evidence from Guatemala. Journal of Development Economics, 94(1), 41-61.

DeFranzo, James (1996). Welfare and Burglary. Crime and Delinquency, 42, 223-229.

DeFranzo, James (1997). Welfare and Homicide. Journal of Research in Crime and Delinquency, 34, 395-406.

Dobkin, Carlos and Stephen Puller (2007). The Effects of Government Transfers on Monthly Cycles in Drug Abuse, Hospitalization, and Mortality. Journal of Public Economics, 91(11-12), 2137-57.

Fajnzylber, Pablo, Daniel Lederman, and Norman Loayza (2002). Inequality and violent crime. Journal of Law and Economics, April 2002, 45(1), 1-40.

Fiszbein, Ariel and Norbert Schady (2009). Conditional Cash Transfers: Reducing Present and Future Poverty. World Bank, Washington DC.

Foley, C. Fritz (2008). "Welfare Payments and Crime." NBER Working Paper 14074.

Gottfredson, Denise C. and David A. Soulé (2005). The Timing of Property Crime, Violent Crime, and Substance Use among Juveniles. Journal of Research in Crime and Delinquency, 42(110), 110-120.

Gould, Eric D., Bruce A. Weinberg, and David B. Mustard (2002). Crime Rates and Local Labor Market Opportunities in the United States: 1979-1997. Review of Economics and Statistics, 84(1), 45-61.

Grogger, Jeffrey (1997). Local Violence and Educational Attainment. Journal of Human Resources, 32(4), 659682. 
Hannon, Lance, and James DeFranzo (1998). Welfare and Property Crime. Justice Quarterly, 15, $273-287$.

Heller, Sara B., Brian A. Jacob and Jens Ludwig (2011). Family Income, Neighborhood Poverty, and Crime. In: P. Cook, J. Ludwig and J. McCrary (eds.), Controlling Crime: Strategies and Tradeoffs, University of Chicago Press, 419-459.

Jacob, Brian A. and Lars Lefgren (2003). Are Idle Hands the Devil's Workshop? Incapacitation, Concentration, and Juvenile Crime. American Economic Review, 93(5), 1560-1577.

Jacob, Brian A. and Jens Ludwig (2010). The Effects of Family Resources on Children's Outcomes. Working Paper, University of Michigan.

Levitt, Steven D. and Lance Lochner (2001). The Determinants of Juvenile Crime. In: J. Gruber (ed.), Risky Behavior among Youths: An Economic Analysis, University of Chicago Press, 327-373.

Lochner, Lance and Enrico Moretti (2004). The Effect of Education on Crime: Evidence from Prison Inmates, Arrests, and Self-Reports. American Economic Review, 94(1), 155-189.

Lochner, Lance (2010). “Education Policy and Crime.” NBER Working Paper 15894.

Loureiro, André (2012). “Can Conditional Cash Transfers Reduce Crime? Evidence from Brazil.” Unpublished manuscript.

Luallen, Jeremy (2006). School's out. . . forever: A study of juvenile crime, at-risk youths and teacher strikes. Journal of Urban Economics, 59(1), 75-103.

Rodríguez, Catherine and Fabio Sánchez (2009). "Armed Conflict Exposure, Human Capital Investments and Child Labor: Evidence from Colombia." Serie Documentos CEDE 2009-05, Universidad de Los Andes.

Snyder, Howard N. and Melissa Sickmund (1999). Juvenile Offenders and Victims: 1999 National Report. US Department of Justice Programs, Office of Juvenile Justice and Delinquency Prevention, Washington DC.

Soares, Rodrigo R. (2004). Development, crime, and punishment: Accounting for the international differences in crime rates. Journal of Development Economics, 73(1), 155-184.

Soares, Rodrigo R. and Joana Naritomi (2010). Understanding High Crime Rates in Latin America: The Role of Social and Policy Factors. In: Rafael Di Tella, Sebastian Edwards, and Ernesto Schargrodsky (eds). The Economics of Crime: Lessons for and from Latin America, University of Chicago Press, 2010, 19-55.

Soares, Sergei and Natália Sátyro (2009). "O Programa Bolsa Família: Desenho Institucional, Impactos e Possibilidades Futuras." IPEA Working Paper n1424.

Wooldridge, Jeffrey (2002). Econometric Analysis of Cross Section and Panel Data, MIT Press.

Zhang, Junsen (1997). The Effect of Welfare Programs on Criminal Behavior: A Theoretical and Empirical Analysis. Economic Inquiry, XXXV(1),120-137. 
APPENDIX A

Figure A.1 - Distribution of Number of Crimes per School

Histograms: All Crimes

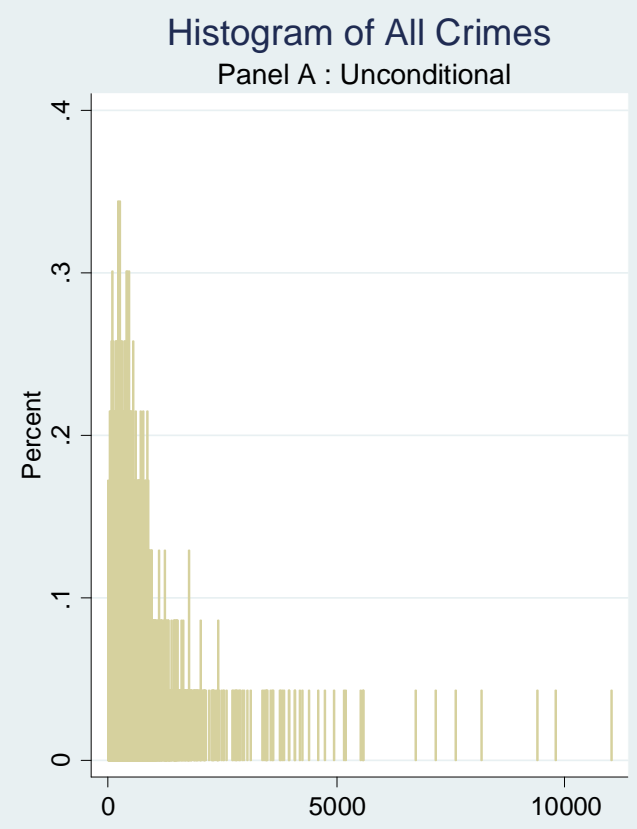

Histogram of All Crimes

Panel B : Conditional on less than 200 occurences

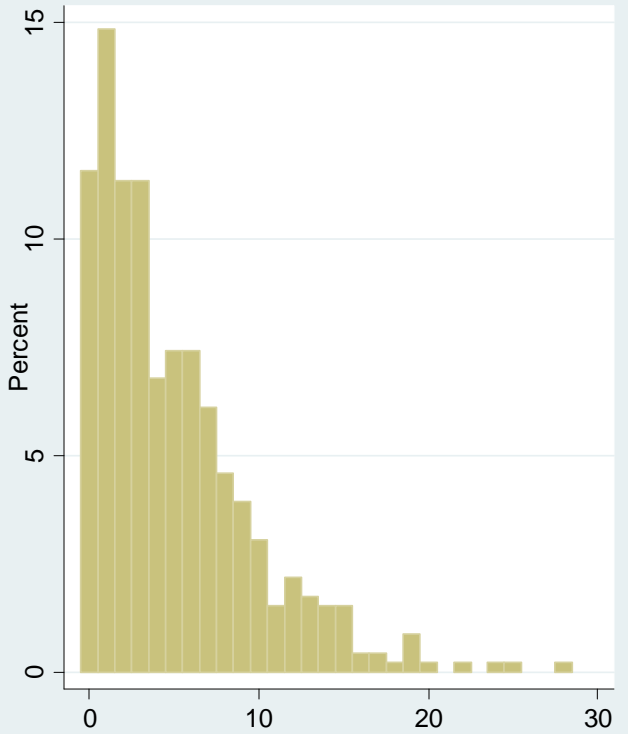




\begin{tabular}{|c|c|c|c|c|c|c|c|}
\hline Panel A: Middle Schools & Mean & $\begin{array}{c}\text { Std } \\
\text { Deviation }\end{array}$ & $\begin{array}{c}25 \text { th } \\
\text { percentile }\end{array}$ & Median & $\begin{array}{c}\text { 75th } \\
\text { percentile }\end{array}$ & $\begin{array}{c}\# \\
\text { Schools }\end{array}$ & \# Obs \\
\hline All Crimes & 377 & 561 & 132 & 240 & 408 & 975 & 3900 \\
\hline$\%$ 16-17 in 2006 & $15 \%$ & $13 \%$ & $3 \%$ & $13 \%$ & $27 \%$ & 975 & 975 \\
\hline \# receiving Bolsa Família & 166 & 115 & 82 & 139 & 220 & 975 & 3900 \\
\hline \# students & 1248 & 457 & 899 & 1194 & 1564 & 975 & 3900 \\
\hline Panel B: High Schools & Mean & $\begin{array}{c}\text { Std } \\
\text { Deviation }\end{array}$ & $\begin{array}{c}25 \text { th } \\
\text { percentile }\end{array}$ & Median & $\begin{array}{c}\text { 75th } \\
\text { percentile }\end{array}$ & $\begin{array}{c}\# \\
\text { Schools }\end{array}$ & \# Obs \\
\hline All Crimes & 634 & 761 & 235 & 447 & 767 & 581 & 2324 \\
\hline$\%$ 16-17 in 2006 & $28 \%$ & $11 \%$ & $20 \%$ & $28 \%$ & $33 \%$ & 581 & 581 \\
\hline \# receiving Bolsa Família & 124 & 95 & 57 & 102 & 170 & 581 & 2324 \\
\hline \# students & 1360 & 499 & 853 & 1345 & 1721 & 581 & 2324 \\
\hline $\begin{array}{l}\text { Panel C: Middle and High } \\
\text { Schools Together }\end{array}$ & Mean & $\begin{array}{c}\text { Std } \\
\text { Deviation }\end{array}$ & $\begin{array}{c}25 \text { th } \\
\text { percentile }\end{array}$ & Median & $\begin{array}{c}\text { 75th } \\
\text { percentile }\end{array}$ & $\begin{array}{c}\# \\
\text { Schools }\end{array}$ & \# Obs \\
\hline All crimes reported & 356 & 521 & 125 & 230 & 395 & 1035 & 4140 \\
\hline$\% 16-17$ in 2006 & $17 \%$ & $15 \%$ & $3 \%$ & $15 \%$ & $30 \%$ & 1035 & 1035 \\
\hline \# receiving Bolsa Família & 162 & 116 & 79 & 135 & 216 & 1035 & 4140 \\
\hline \# students & 1251 & 457 & 898 & 1194 & 1567 & 1035 & 4140 \\
\hline
\end{tabular}




\begin{tabular}{|c|c|c|c|c|c|}
\hline Panel A: Middle Schools & $\begin{array}{c}(1) \\
\text { OLS } \\
\end{array}$ & $\begin{array}{c}\text { (2) } \\
\text { OLS } \\
\end{array}$ & $\begin{array}{c}\text { (3) } \\
\text { OLS } \\
\end{array}$ & $\begin{array}{c}\text { (4) } \\
\text { Reduced- } \\
\text { form } \dagger\end{array}$ & $\begin{array}{l}\text { (5) } \\
I V \neq\end{array}$ \\
\hline Bolsa Família & $\begin{array}{c}-0.00224 * * * \\
{[0.000254]}\end{array}$ & $\begin{array}{c}-0.00157 * * * \\
{[0.000296]}\end{array}$ & $\begin{array}{c}5.04 \mathrm{e}-05 \\
{[0.000234]}\end{array}$ & & $\begin{array}{c}-0.000920 * * * \\
{[0.000290]}\end{array}$ \\
\hline Instrument & & & & $\begin{array}{c}-0.000129 * * * \\
{[4.64 \mathrm{e}-05]}\end{array}$ & \\
\hline Controls? & No & Yes & Yes & Yes & Yes \\
\hline School Fixed Effects? & No & No & Yes & Yes & Yes \\
\hline$R^{2}$ & 0.062 & 0.165 & 0.949 & 0.949 & \\
\hline Observations & 3,900 & 3,726 & 3,726 & 3,726 & 3,726 \\
\hline Panel B: High Schools & OLS & OLS & OLS & $\begin{array}{c}\text { (4) } \\
\text { Reduced- } \\
\text { form } \dagger\end{array}$ & IV \\
\hline Bolsa Família & $\begin{array}{c}-0.00396 * * * \\
{[0.000419]}\end{array}$ & $\begin{array}{c}-0.00384 * * * \\
{[0.000506]}\end{array}$ & $\begin{array}{c}6.46 \mathrm{e}-05 \\
{[0.000276]}\end{array}$ & & $\begin{array}{c}-0.00391 * * * \\
{[0.00141]}\end{array}$ \\
\hline Instrument & & & & $\begin{array}{c}-0.000147 * * * \\
{[5.53 \mathrm{e}-05]}\end{array}$ & \\
\hline Controls? & No & Yes & Yes & Yes & Yes \\
\hline School Fixed Effects? & No & No & Yes & Yes & Yes \\
\hline$R^{2}$ & 0.130 & 0.334 & 0.967 & 0.967 & \\
\hline Observations & 2,324 & 2,233 & 2,233 & 2,233 & 2,233 \\
\hline Panel C: Middle and High & (1) & (2) & (3) & (4) & (5) \\
\hline Schools Together & OLS & OLS & OLS & $\begin{array}{l}\text { Reduced- } \\
\text { form } \dagger\end{array}$ & IV \\
\hline Bolsa Família & $\begin{array}{c}-0.00235^{* * *} * \\
{[0.000247]}\end{array}$ & $\begin{array}{c}-0.00147 * * * \\
{[0.000281]}\end{array}$ & $\begin{array}{c}3.67 \mathrm{e}-05 \\
{[0.000221]}\end{array}$ & & $\begin{array}{c}-0.00110^{* * * *} \\
{[0.000284]}\end{array}$ \\
\hline Instrument & & & & $\begin{array}{c}-0.000133 * * * \\
{[3.90 \mathrm{e}-05]}\end{array}$ & \\
\hline Controls? & No & Yes & Yes & Yes & Yes \\
\hline School Fixed Effects? & No & No & Yes & Yes & Yes \\
\hline$R^{2}$ & 0.068 & 0.196 & 0.949 & 0.949 & 0.947 \\
\hline Observations & 4,140 & 3,958 & 3,958 & 3,958 & 3,958 \\
\hline \multicolumn{6}{|c|}{$\begin{array}{l}\text { Source: Standard errors in parentheses robust to clustering at the school level. * significant at } 10 \% ; * * \text { significant at } 5 \% \text {; *** significant at } 1 \% \text {. Unit of } \\
\text { observation is a school. Dependent variable is the log of the sum of all crimes that occurred in a school neighborhood (Panel A for Middle Schools, Panel B } \\
\text { for High Schools and Panel C for Middle and High Schools together). Coefficient is a semi-elasticity. The crime is attributed to the closest school. Controls: } \\
\text { Year dummies, school size (number of students), average teachers' years of schooling, student-to-teacher ratio, number of students per class, dummy for } \\
\text { sewage at the school, proportion of girls, proportion of non-whites, dummy for the presence of TV in the school, dummy for water system at the school, } \\
\text { proportion of students older than the normal grade age and a dummy for whether computers are available for students. } \dagger: \text { Reduced-form, dependent variable } \\
\text { regressed on exogenous covariates and the instrument. } \$: \text { Instrument is the number of } 16 \text { and } 17 \text { year-olds at the school in } 2006 \text { interacted with a dummy for } \\
\text { years } 2008 \text { and } 2009 \text {. }\end{array}$} \\
\hline
\end{tabular}


Table 3 - First Stage: Bolsa Família Regressed on Instrument, High Schools

Instrument $\$$

Controls?

School Fixed Effects?

$R^{2}$

$F$-statistic of Instrument

Observations
(1)

(2)

$-0.0103$

[0.0163]

No

No

0.084

0.401

2,324
(3)

$0.0174 * *$

[0.00823]

$0.0376^{* * *}$

[0.00782]

Yes

Yes

0.925

23.10

2,233

Source: Standard errors in parentheses robust to clustering at the school level. * significant at $10 \%$; ** significant at $5 \%$; *** significant at $1 \%$. Unit of observation is a school. Dependent variable is the number of Bolsa Família recipients in the school (Panel A for Middle Schools, Panel B for High Schools and Panel C for Middle and High Schools together). Controls: Year dummies, school size (number of students), average teacher years of schooling, student-to-teacher ratio, number of students per class, dummy for sewage at the school, proportion of girls, proportion of non-whites, dummy for the presence of TV in the school, dummy for water system at the school, proportion of students older than the normal grade age and a dummy for whether computers are available for students. $\$$ : Instrument is the number of 16 and 17 year-olds at the school in 2006 interacted with years 2008 and 2009. 
Table 4 - Incorporating Renda Mínima and Neighboring Schools: Effect of CCT on Crime, High Schools

(1)

(2)

(3)

(4)

(5)

Bolsa Família and Renda Mínima

Renda Mínima, ignoring Bolsa

Família

$\begin{array}{ccc}1^{\text {st }} \text { stage for CCT }= & 2^{\text {nd }} \text { stage for CCT } & \text { CCT }=\text { Bolsa } \\ \text { Bolsa Família }+ & =\text { Bolsa Família }+ & \text { Família, } \text { Renda } \\ \text { Renda Mínima } & \text { Renda Mínima } & \text { Mínima } \text { as control }\end{array}$
$1^{\text {st }}$ stage for CCT $=2^{\text {nd }}$ stage for CCT
Renda Mínima = Renda Mínima

(6)

Accounting for

Neighbors

$-0.00417 * * \quad-0.00377 * * *$

[0.00176]

[0.00131]

0.0626

[0.00135]

CCT

$0.00219 * * *$

[0.117]

Família
CCT

Renda Mínima as Control

$\begin{array}{cc}0.03524 * * \\ \text { Instrument } \$ & {[0.0113]}\end{array}$

[0.000697]

$-0.00235$

[0.00508]

Students in Schools within $2 \mathrm{Kms}$

$0.000091 * * *$

[0.0000298]

$\begin{array}{lccccc}\text { Controls? } & \text { Yes } & \text { Yes } & \text { Yes } & \text { Yes } & \text { Yes } \\ \text { ol Fixed Effects? } & \text { Yes } & \text { Yes } & \text { Yes } & \text { Yes } & \text { Yes } \\ \text { Observations } & 2,233 & 2,233 & 2,233 & 2,233 & 2,233\end{array}$

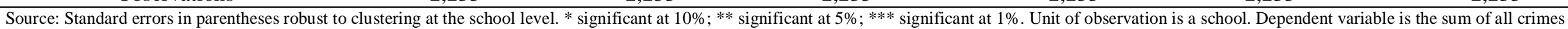

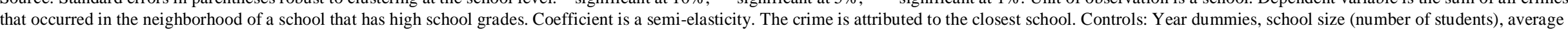

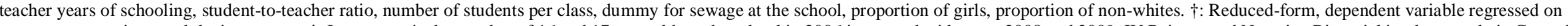

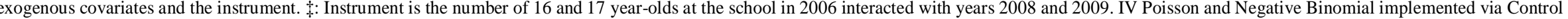

Function (standard errors are bootstrapped with 400 replications) 
Table 5 - Count Models: Effect of Bolsa Família on Crime with Alternative Functional Forms, High Schools

(1)

(2)

(3)

(4)

(5)

(6)

Reduced-form,

Poisson

Poisson

Poisson Poisson $\dagger$

IV - Poisson $\neq$

IV - Negative

\begin{tabular}{cccc} 
& Poisson & Poisson & Poisson \\
\hline & & & \\
Bolsa Família & $-0.00465 * * *$ & $-0.00620 * * *$ & 0.000148 \\
& {$[0.000514]$} & {$[0.000999]$} & {$[0.000146]$}
\end{tabular}

Instrument

Residual First Stage

$\begin{array}{cc}0.00283 * * * & 0.00356 * * * \\ {[0.00117]} & {[0.00132]}\end{array}$

Controls?

\begin{tabular}{|c|c|c|c|c|c|c|}
\hline Controls? & No & Yes & Yes & Yes & Yes & Yes \\
\hline School Fixed Effects? & No & No & Yes & Yes & Yes & Yes \\
\hline Observations & 2,324 & 2,323 & 2,323 & 2,323 & 2,323 & 2,32 \\
\hline
\end{tabular}

\begin{tabular}{|c|c|c|c|c|c|c|}
\hline Controls? & No & Yes & Yes & Yes & Yes & Yes \\
\hline School Fixed Effects? & No & No & Yes & Yes & Yes & Yes \\
\hline Observations & 2,324 & 2,323 & 2,323 & 2,323 & 2,323 & \\
\hline
\end{tabular}

\begin{tabular}{ccccccc} 
Controls? & No & Yes & Yes & Yes & Yes & Yes \\
School Fixed Effects? & No & No & Yes & Yes & 2,323 & 2,323 \\
Observations & 2,324 & 2,323 & 2,323 & Yes \\
\hline
\end{tabular}

Source: Standard errors in parentheses robust to clustering at the school level. * significant at 10\%; ** significant at 5\%; *** significant at $1 \%$. Unit of observation is a school. Dependent variable

is the sum of all crimes that occurred in the neighborhood of a school that has high school grades. Coefficient is a semi-elasticity. The crime is attributed to the closest school. Controls: Yea

dummies, school size (number of students), average teacher years of schooling, student-to-teacher ratio, number of students per class, dummy for sewage at the school, proportion of girls,

proportion of non-whites. $\uparrow$ : Reduced-form, dependent variable regressed on exogenous covariates and the instrument. $\ddagger$ Instrument is the number of 16 and 17 year-olds at the school in 2006 interacted with years 2008 and 2009. IV Poisson and Negative Binomial implemented via Control Function (standard errors are bootstrapped with 400 replications). 
Table 6 - Day and Time: Effect of Bolsa Família on Crime by Day and Time of Occurrence, IV Regressions for High Schoolst

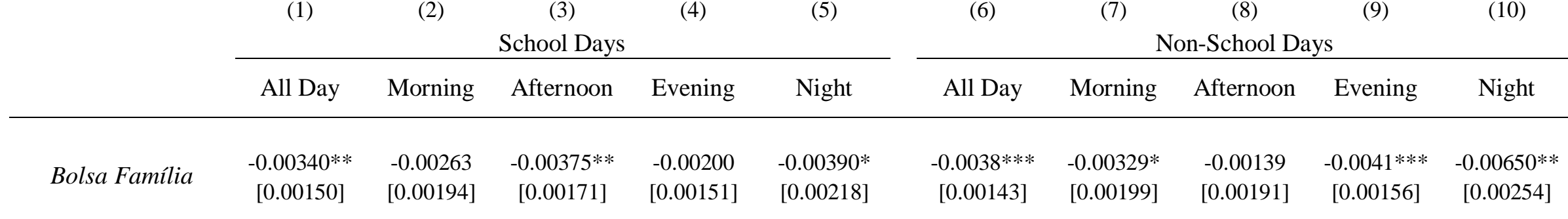

\begin{tabular}{|c|c|c|c|c|c|c|c|c|c|c|}
\hline Controls? & Yes & Yes & Yes & Yes & Yes & Yes & Yes & Yes & Yes & Yes \\
\hline School Fixed Effects? & Yes & Yes & Yes & Yes & Yes & Yes & Yes & Yes & Yes & Yes \\
\hline$R^{2}$ & 0.952 & 0.905 & 0.916 & 0.949 & 0.866 & 0.943 & 0.885 & 0.897 & 0.926 & 0.855 \\
\hline Observations & 2,233 & 2,233 & 2,233 & 2,233 & 2,233 & 2,233 & 2,233 & 2,233 & 2,233 & 2,233 \\
\hline
\end{tabular}

Source: Standard errors in parentheses robust to clustering at the school level. * significant at 10\%; ** significant at 5\%; *** significant at $1 \%$. Unit of observation is a school. Dependent variable is the sum of all crimes in a certain category that occurred in the neighborhood of a school that has high-school grades. Coefficient is a semi-elasticity. The crime is attributed to the closest school. Controls: Year dummies,

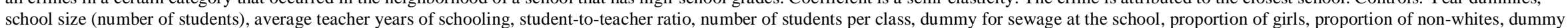

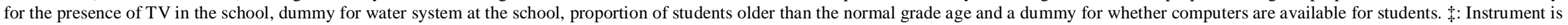
the number of 16 and 17 year-olds at the school in 2006 interacted with years 2008 and 2009. 


\begin{tabular}{|c|c|c|c|c|c|c|}
\hline & (1) & (2) & (3) & (4) & (5) & (6) \\
\hline & Robbery & Theft & $\begin{array}{l}\text { Violent } \\
\text { Crime }\end{array}$ & Vandalism & Drug-related & $\begin{array}{l}\text { Against } \\
\text { Minors }\end{array}$ \\
\hline Bolsa Família & $\begin{array}{c}-0.00464 * * * \\
{[0.00179]}\end{array}$ & $\begin{array}{c}-0.00118 \\
{[0.00195]}\end{array}$ & $\begin{array}{l}-0.00252 * \\
{[0.00146]}\end{array}$ & $\begin{array}{l}0.000143 \\
{[0.00279]}\end{array}$ & $\begin{array}{c}-0.0150^{* * * *} \\
{[0.00435]}\end{array}$ & $\begin{array}{c}-0.00782 * * \\
{[0.00371]}\end{array}$ \\
\hline Controls? & Yes & Yes & Yes & Yes & Yes & Yes \\
\hline School Fixed Effects? & Yes & Yes & Yes & Yes & Yes & Yes \\
\hline Observations & 2,233 & 2,233 & 2,233 & 2,233 & 2,233 & 2,233 \\
\hline \multicolumn{7}{|c|}{$\begin{array}{l}\text { Source: Standard errors in parentheses robust to clustering at the school level. * significant at } 10 \% \text {; ** significant at } 5 \% \text {; *** significant at } 1 \% \text {. Unit of observation is } \\
\text { a school. Dependent variable is the sum of all crimes in a certain category that occurred in the neighborhood of a school that has high-school grades. Coefficient is a } \\
\text { semi-elasticity. The crime is attributed to the closest school. Controls: Year dummies, school size (number of students), average teacher years of schooling, student- } \\
\text { to-teacher ratio, number of students per class, dummy for sewage at the school, proportion of girls, proportion of non-whites, dummy for the presence of TV in the } \\
\text { school, dummy for water system at the school, proportion of students older than the normal grade age and a dummy for whether computers are available for students. } \\
\text { s: Instrument is the number of } 16 \text { and } 17 \text { year-olds at the school in } 2006 \text { interacted with years } 2008 \text { and } 2009 \text {. }\end{array}$} \\
\hline
\end{tabular}

